\title{
In-Situ Growth of NiAl-Layered Double Hydroxide on AZ31 Mg Alloy towards Enhanced Corrosion Protection
}

\author{
Xin Ye ${ }^{1}$, Zimin Jiang ${ }^{2}$, Linxin $\mathrm{Li}^{1}$ and Zhi-Hui Xie ${ }^{1, *}$ \\ 1 Chemical Synthesis and Pollution Control Key Laboratory of Sichuan Province, China West Normal \\ University, Nanchong 637002, China; xinchem4@163.com (X.Y.); Linxinyj@163.com (L.L.) \\ 2 College of Foreign Language Education, China West Normal University, Nanchong 637002, China; \\ jenny8116@126.com \\ * Correspondence: zhxie@cwnu.edu.cn; Tel./Fax: +86-817-256-8081
}

Received: 20 May 2018; Accepted: 1 June 2018; Published: 7 June 2018

\begin{abstract}
NiAl-layered double hydroxide (NiAl-LDH) coatings grown in-situ on AZ31 Mg alloy were prepared for the first time utilizing a facile hydrothermal method. The surface morphologies, structures, and compositions of the NiAl-LDH coatings were characterized by scanning electron microscopy (SEM), three dimensional (3D) optical profilometer, X-ray diffractometer (XRD), Fourier transform infrared spectrometer (FT-IR), and X-ray photoelectron spectroscopy (XPS). The results show that NiAl-LDH coating could be successfully deposited on Mg alloy substrate using different nickel salts, i.e., carbonate, nitrate, and sulfate salts. Different coatings exhibit different surface morphologies, but all of which exhibit remarkable enhancement in corrosion protection in $3.5 \mathrm{wt} \% \mathrm{NaCl}$ corrosive electrolyte. When nickel nitrate was employed especially, an extremely large impedance modulus at a low frequency of $0.1 \mathrm{~Hz}\left(|\mathrm{Z}|_{f=0.1 \mathrm{~Hz}}\right), 11.6 \mathrm{M} \Omega \mathrm{cm}^{2}$, and a significant low corrosion current density $\left(j_{\text {corr }}\right)$ down to $1.06 \mathrm{nA} \mathrm{cm}^{-2}$ are achieved, demonstrating NiAl-LDH coating's great potential application in harsh reaction conditions, particularly in a marine environment. The best corrosion inhibition of NiAl-LDH/CT coating deposited by carbonate may partially ascribed to the uniform and vertical orientation of the nanosheets in the coating.
\end{abstract}

Keywords: Mg alloy; LDH; corrosion; deposition; coating

\section{Introduction}

Mg alloy has excellent physical and mechanical properties but a high chemical reactivity and susceptibility to corrosion, which hinders its practical application and development in more fields [1]. Efforts by formation of protective coatings on $\mathrm{Mg}$ alloy surface to decrease the corrosion rate and extend the serving time have aroused an increasing interest in the area of surface engineering [1,2]. Many traditional coating methods are adopted to protect $\mathrm{Mg}$ alloy from corrosion, such as electroless Ni plating [3,4]. However, more and more attendant problems, especially environmental issues, emerge with increasing usage of these techniques, such as the high cost and complexity in dealing with the waste plating bath, and the detrimental effect of $\mathrm{Cr}$ to the ecosystem [3]. Thus, it is highly urgent to find state-of-the-art alternative coatings with low pollution emissions but with efficient corrosion inhibition.

Layered double hydroxides (LDHs) have received extensive attention for potential application in supercapacitor [5], catalysis [6], adsorbents [7], and corrosion protection [8] because of their diversity in compositions and structures. The charge of the metal layer in the LDHs is compensated by interlayer anions such as $\mathrm{CO}_{3}{ }^{2-}$. Once $\mathrm{CO}_{3}{ }^{2-}$ anions are intercalated, it cannot be exchanged by most corrosive anions, such as $\mathrm{SO}_{4}{ }^{2-}$ and $\mathrm{Cl}^{-}$, due to the high ion-exchange equilibrium constant of $\mathrm{CO}_{3}{ }^{2-}$ anions, 
thereby the corrosion of the substrate under the LDHs coating will be delayed. From this point of view, $\mathrm{CO}_{3}{ }^{2-}$ anions intercalated LDHs are an ideal choice for obtaining a LDHs coating with high corrosion inhibition capacity. The most widely reported $\mathrm{CO}_{3}{ }^{2-}$ intercalated $\mathrm{LDHs}$ on $\mathrm{Mg}$ alloy matrix is MgAl-LDHs coating, which is obtained, in most cases, by in-situ growth technology owing to the simplification of operation and strong adhesion of the coating [9]. Recently, MgFe-LDH and $\mathrm{MgCr}-\mathrm{LDH}$ films were also obtained on anodized AZ31 Mg alloy by in-situ growth measurement [10]. However, the orders of magnitude of the $j_{\text {corr }}$ of these in-situ grown LDH coatings are higher than -8 , mostly range from -5 to -7 (Table 1 ) $[8,11-14]$. To break the bottleneck of $j_{\text {corr }}$, it is advisable to prepare carbonate-based LDHs film by attempting more different divalent or trivalent metallic cations. Though most recent research results proved that NiAl-LDH nanoparticles possess good photocatalytic performance [15], in-situ growth of NiAl-LDH film on Mg alloy for corrosion protection has not yet been reported to date.

Table 1. Corrosion inhibition of different layered double hydroxide (LDH) coatings on Mg alloy from most recent published literature.

\begin{tabular}{|c|c|c|c|c|c|}
\hline Substrate & LDH Coatings & Corrosive Medium & $\begin{array}{c}E_{\text {corr }} \\
\text { V vs. SCE }\end{array}$ & $\begin{array}{c}j_{\text {corr }} \\
\left(\mathrm{A} \mathrm{cm}^{-2}\right)\end{array}$ & Ref. \\
\hline Mg alloy & $\mathrm{MgAl}-\mathrm{NO}_{3}{ }^{-}$ & Phosphate buffer saline & -1.53 & $3.63 \times 10^{-7}$ & [14] \\
\hline Anodized AZ31 Mg alloy & $\mathrm{MgAl}-\mathrm{VO}_{3}^{-}$ & $3.5 \mathrm{wt} \% \mathrm{NaCl}$ solution & -0.40 & $2.48 \times 10^{-7}$ & [8] \\
\hline Anodized AZ31 Mg alloy & $\mathrm{MgAl}-\mathrm{NO}_{3}{ }^{-}$ & $3.5 \mathrm{wt} \% \mathrm{NaCl}$ solution & -1.34 & $1.18 \times 10^{-7}$ & [10] \\
\hline AZ31 Mg alloy & MgAl-5-fluorouracil & Phosphate buffer saline & -1.12 & $3.34 \times 10^{-5}$ & [13] \\
\hline AZ31 Mg alloy & MgAl-5-fluorouracil & Phosphate buffer saline & -1.42 & $3.27 \times 10^{-5}$ & [16] \\
\hline Anodized AZ31 Mg alloy & $\mathrm{MgFe}-\mathrm{NO}_{3}{ }^{-}$ & $3.5 \mathrm{wt} \% \mathrm{NaCl}$ solution & -1.44 & $1.09 \times 10^{-6}$ & [10] \\
\hline Anodized AZ31 Mg alloy & $\mathrm{MgCr}-\mathrm{NO}_{3}^{-}$ & $3.5 \mathrm{wt} \% \mathrm{NaCl}$ solution & -1.47 & $2.16 \times 10^{-6}$ & [10] \\
\hline AZ91D Mg alloy & $\mathrm{ZnAl-}-\mathrm{VO}_{3}{ }^{-}$ & 3.5 wt $\% \mathrm{NaCl}$ solution & -1.30 & $2.21 \times 10^{-6}$ & [17] \\
\hline AZ91D Mg alloy & $\mathrm{ZnAl}-\mathrm{Cl}^{-}$ & $3.5 \mathrm{wt} \% \mathrm{NaCl}$ solution & -1.39 & $2.52 \times 10^{-6}$ & [17] \\
\hline AZ91D Mg alloy & $\mathrm{ZnAl}-\mathrm{NO}_{3}{ }^{-}$ & $3.5 \mathrm{wt} \% \mathrm{NaCl}$ solution & -1.42 & $1.33 \times 10^{-5}$ & [17] \\
\hline
\end{tabular}

Herein, we report a facile hydrothermal measurement to in-situ growth of NiAl-LDH nanocomposite on $\mathrm{Mg}$ alloy by use of alkaline solutions with three different nickel salts for preparation of a highly enhanced corrosion-resistant coating with an extraordinary low corrosion rate (Figure 1). The NiAl-LDH coating prepared by nickel carbonate exhibits uniformly and vertically aligned nanoarrays with an extremely large impedance modulus at a low frequency of $0.1 \mathrm{~Hz}\left(|Z|_{f=0.1 \mathrm{~Hz}}\right)$, $11.6 \mathrm{M} \Omega \mathrm{cm}^{2}$, and a significantly low $j_{\text {corr }}$ down to $1.06 \mathrm{nA} \mathrm{cm}^{-2}$ in $3.5 \mathrm{wt} \% \mathrm{NaCl}$ corrosive electrolyte, which outperforms the values of the foregoing achieved $\mathrm{LDH}$ coating on $\mathrm{Mg}$ alloy (Table 1) $[8,10,13,14,16-18]$. The NiAl-LDH coatings were characterized, and the enhanced corrosion inhibition mechanism was proposed and discussed. 


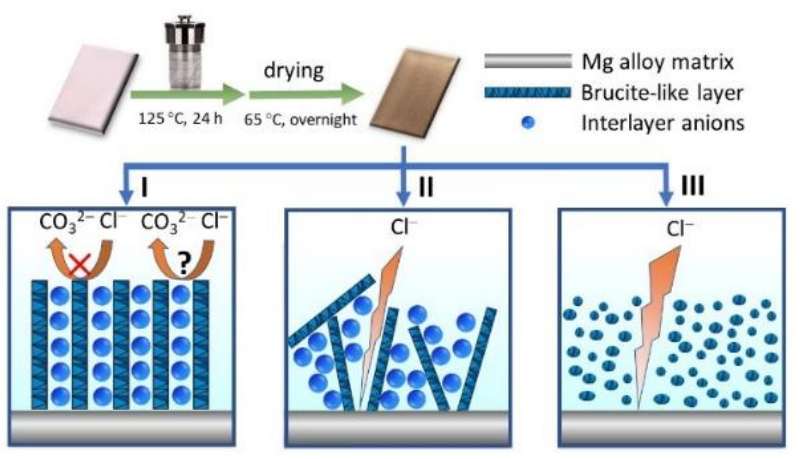

Figure 1. Schematic illustration of various microstructures of NiAl-LDH coatings prepared with different nickel salts. (I) nickel carbonate; (II) nickel nitrate; and (III) nickel sulfate. The interlayer anions are not given in case III.

\section{Methods}

\subsection{Materials and Reagents}

The matrix used is AZ31 Mg alloy with a chemical composition in wt \%: $2.75 \mathrm{Al}, 1.15 \mathrm{Zn}$, $0.16 \mathrm{Mn}$, and $\mathrm{Mg}$ balance. Primary chemicals include nickel carbonate (AR), nickel nitrate ( $\geq 98 \%)$, nickel sulphate $(\geq 98.5 \%)$, sodium carbonate $(\geq 99.8 \%)$, and sodium hydroxide $(\geq 98 \%)$. Chemicals were acquired from Aladdin Industrial Inc. (Shanghai, China) and Sinopharm Chemical Reagent Co., Ltd. (Shanghai, China), and all chemicals were used without further purification. Ultrapure water used in the experiments was obtained using a water purification system (UPT-II-10T, Ulupure Corporation, Chengdu, China) with a resistivity of $18.2 \mathrm{M} \Omega \mathrm{cm}$ at $25^{\circ} \mathrm{C}$.

\subsection{Preparation of NiAl-LDH Coatings on $\mathrm{Mg}$ Alloy}

All the NiAl-LDH coatings were grown on Mg alloy substrate by a simple one step hydrothermal method with the same steps and conditions but with three different nickel salts. The obtained coatings by use of nickel carbonate, nickel nitrate, and nickel sulphate are denoted as NiAl-LDH/CT, $\mathrm{NiAl}-\mathrm{LDH} / \mathrm{NT}$, and NiAl-LDH/ST coatings, respectively. The mole ratio of $\mathrm{Ni}^{2+}, \mathrm{Al}^{3+}$, and $\mathrm{CO}_{3}{ }^{2-}$ in the precursor solution is 6:2:1. Take the preparation of NiAl-LDH/CT coating, for example, which is described as follows:

Pre-treatment of substrate: The AZ31 Mg alloy was ground mechanically with $\mathrm{SiC}$ waterproof sand paper and degreased in an alkaline solution at $65^{\circ} \mathrm{C}$ for $10 \mathrm{~min}$ [3].

Preparation of precursor solution: $40 \mathrm{~mL}$ aluminum nitrate solution $\left(0.002 \mathrm{~mol} \mathrm{Al}\left(\mathrm{NO}_{3}\right)_{3} \cdot 9 \mathrm{H}_{2} \mathrm{O}\right)$ was first added to a nickel solution $(\sim 40 \mathrm{~mL})$ containing $0.002 \mathrm{~mol} \mathrm{NiCO} 3 \cdot 2 \mathrm{Ni}(\mathrm{OH})_{2} \cdot 4 \mathrm{H}_{2} \mathrm{O}$. Then, $0.001 \mathrm{~mol}$ anhydrous $\mathrm{Na}_{2} \mathrm{CO}_{3}$ was added, followed by $\mathrm{pH}$ adjustment of the solution to about 12 by use of a $\mathrm{NaOH}$ solution $(\sim 3.7 \mathrm{~mL})$. Finally, the above solution was diluted to a volume of $100 \mathrm{~mL}$ by adding ultrapure water.

Growth of NiAl-LDH film: The solution above was then transferred into a $100 \mathrm{~mL}$ Teflon-lined autoclave where a pre-treated $\mathrm{Mg}$ alloy has been placed. Then, the autoclave was placed and kept in an oven with a temperature of $125^{\circ} \mathrm{C}$ for $24 \mathrm{~h}$ for in-situ growth of NiAl-LDH films on the matrix.

After that, the samples were taken out of the autoclave, rinsed with water, dried overnight in an oven at $65^{\circ} \mathrm{C}$, and designed as NiAl-LDH/CT coating. The amount of nickel salts is 0.006 mol for deposition of NiAl-LDH/NT and NiAl-LDH/ST coatings, which is the sole difference in comparison with preparation of $\mathrm{NiAl}-\mathrm{LDH} / \mathrm{CT}$ coating.

\subsection{Characterization and Electrochemical Tests}

The surface morphologies and roughness of the different NiAl-LDH coatings were observed by scanning electron microscopy (SEM, Hitachi S-4800, Hitachi High-Technologies 
Corporation, Tokyo, Japan), and three dimensional (3D) optical profilometer (Bruker Contour GT-K, Billerica, MA, USA), respectively. The arithmetical mean deviation of the profile $\left(R_{\mathrm{a}}\right)$ is used to estimate the roughness. The microstructures of the coatings were identified by $\mathrm{X}$-ray diffractometer (XRD, D8 Advance). Fourier transform infrared spectroscopic acquisition of the specimens were obtained (FT-IR, Nicolet 6700, Thermo Scientific, Waltham, MA, USA) in the range of $4000 \sim 500 \mathrm{~cm}^{-1}$. The elemental compositions of the sample surface were recorded by X-ray photoelectron spectroscopy (XPS, 250Xi, Thermo Scientific, Waltham, MA, USA) and energy dispersive X-ray spectroscopy (EDS) equipped in SEM. The water contact angles were measured with a water drop volume of $5 \mu \mathrm{L}$, utilizing optical contact angle meter (JC2000D, Shanghai Zhongchen Digital Technology Apparatus Co., Ltd., Shanghai, China) at 298 K. The electrochemical impedance spectroscopy (EIS) and Tafel curves were achieved using a classical three-electrode system with saturated calomel electrode (SCE) as reference electrode, $\mathrm{Pt}$ foil as counter electrode, and freshly ground bare $\mathrm{Mg}$ alloy and as-prepared NiAl-LDH coatings as working electrode (exposed area: $1 \times 1 \mathrm{~cm}^{2}$ ) on an electrochemical workstation (CHI660E, Chenhua, Shanghai, China). The EIS frequencies range from $10^{5} \sim 0.1 \mathrm{~Hz}$ using an AC perturbation of $10 \mathrm{mV}$ versus the open circuit potential (OCP). The Tafel measurement was performed at a scan rate of $5 \mathrm{mV} / \mathrm{s}$ in the potential region of $\pm 500 \mathrm{mV}$ versus OCP. All the electrochemical tests were carried out in a $3.5 \mathrm{wt} \% \mathrm{NaCl}$ solution at $298 \mathrm{~K}$.

\section{Results and Discussion}

The digital photos of bare Mg alloy and three different NiAl-LDH coatings are shown in Figure 2. The substrate shows a shiny surface after polishing and pre-treatment processes, as shown in Figure 2a. After coating, all the samples show a light bronze-like surface in color, suggesting the successfully deposition of NiAl-LDH coating on the Mg alloy (Figure 2b-d). The surface brightness of $\mathrm{NiAl}-\mathrm{LDH} / \mathrm{CT}$ and NiAl-LDH/NT coatings are very close, and both of which are brighter than that of NiAl-LDH/ST coating.

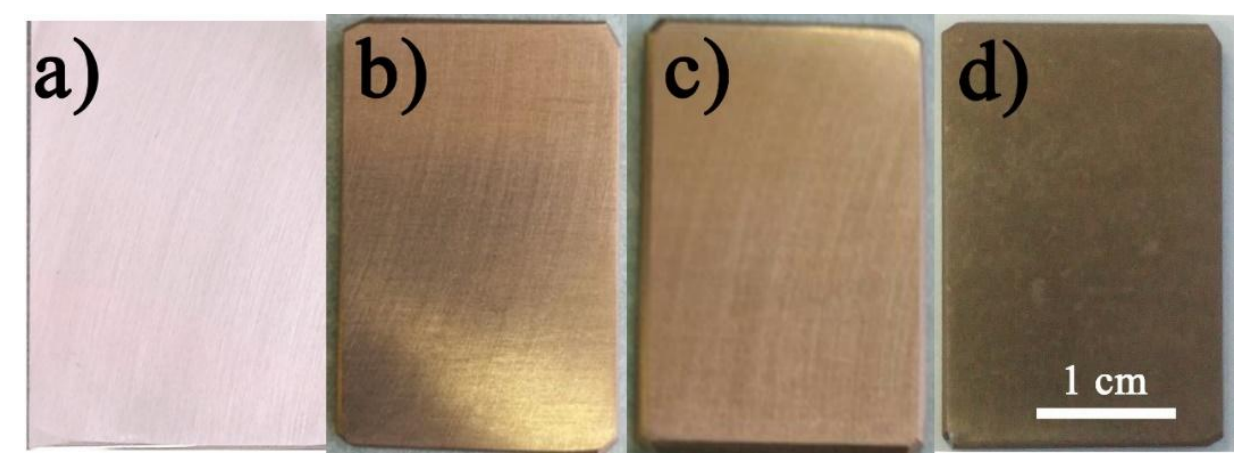

Figure 2. Digital photos of (a) bare Mg alloy; (b) NiAl-LDH/CT; (c) NiAl-LDH/NT; and (d) NiAl-LDH/ST coatings.

Figure 3a shows the XRD patterns of Mg alloy and NiAl-LDH coatings obtained with different nickel salts. For the substrate, three strong peaks at $(2 \theta) 32.20^{\circ}, 34.40^{\circ}$, and $36.62^{\circ}$, and several relatively weak peaks at $47.83^{\circ}, 63.06^{\circ}$, and $72.50^{\circ}$, etc. are ascribed to the characteristic diffraction peaks of $\mathrm{Mg}$ (PDF 35-0821). These small and weak peaks at $18.59^{\circ}, 38.02^{\circ}, 58.64^{\circ}$, and $62.07^{\circ}$ are the characteristic peaks of $\mathrm{Mg}(\mathrm{OH})_{2}$ (PDF 07-0239) [19,20]. The XRD patterns of all coatings are almost identical and two new peaks appear at ca. $11.73^{\circ}$ and $23.58^{\circ}$, which correspond to the (003) and (006) planes of NiAl-LDH (PDF 15-0087) [15]. Figure $3 \mathrm{~b}$ shows that all samples present almost the same absorption peaks in the FT-IR spectra. The relatively strong peak at $3692 \mathrm{~cm}^{-1}$ is related to the O-H stretching vibration of $\mathrm{Ni}-\mathrm{O}-\mathrm{H}$, and the broadening adsorption peaks at $3464 \mathrm{~cm}^{-1}$ and $1630 \mathrm{~cm}^{-1}$ are associated with the $\mathrm{O}-\mathrm{H}$ stretching and bending vibrations from interlamellar water molecules [21] owing to formation of hydrogen-bond. The absorption bands located at 1368 and ca. $1070 \mathrm{~cm}^{-1}$ correspond 
to the asymmetrical and symmetrical stretching vibrations of $\mathrm{C}-\mathrm{O}$ in $\mathrm{CO}_{3}{ }^{2-}$, respectively. The weak bands below $800 \mathrm{~cm}^{-1}$ are assigned to lattice vibrations of metal-oxygen $(\mathrm{M}-\mathrm{O})$ in the brucite-like layers [8]. XPS survey spectrum in Figure $3 \mathrm{c}$ shows that the primary elements of substrate are $\mathrm{Mg}$ and $\mathrm{O}$, and $\mathrm{C}$ 1s peaks is hardly seen. After coating, two new peaks appeared at ca. 856.5 and $74.2 \mathrm{eV}$ which are assigned to $\mathrm{Ni} 2 \mathrm{p}$ and $\mathrm{Al} 2 \mathrm{~s}$, respectively. In addition, significant intensification of $\mathrm{C} 1 \mathrm{~s}$ peak at ca. $284 \mathrm{eV}$ is observed. The Ni 2 p high-resolution XPS spectra exhibit two major peaks along with two pairs of shake-up satellites (Figure 3d). The major peaks at 873.4 and $855.7 \mathrm{eV}$ relating to $\mathrm{Ni}$ $2 \mathrm{p}_{1 / 2}$ and $\mathrm{Ni} 2 \mathrm{p}_{3 / 2}$ with a spin-energy separation of $17.7 \mathrm{eV}$ are characteristics of $\mathrm{Ni}$ (II) in $\mathrm{Ni}(\mathrm{OH})_{2}$. The $\mathrm{Al} 2 \mathrm{p}$ spectra showing peaks at ca. $74.4 \mathrm{eV}$ (Figure $3 \mathrm{e}$ ) are ascribed to $\mathrm{Al}^{3+}$ species (Al-O). The $\mathrm{C} 1 \mathrm{~s}$ spectrum is deconvoluted into three separate peaks related to different types of carbon bonds including $\mathrm{C}-\mathrm{C}$ at $284.8 \mathrm{eV}$ owing to adventitious carbon, $\mathrm{C}-\mathrm{O}(286.3 \mathrm{eV})$ and $\mathrm{O}-\mathrm{C}=\mathrm{O}(288.7 \mathrm{eV})$ from $\mathrm{CO}_{3}{ }^{2-}$ (Figure 3f). These characterizations demonstrate the successful formation of NiAl-LDH crystal phase on the matrix.
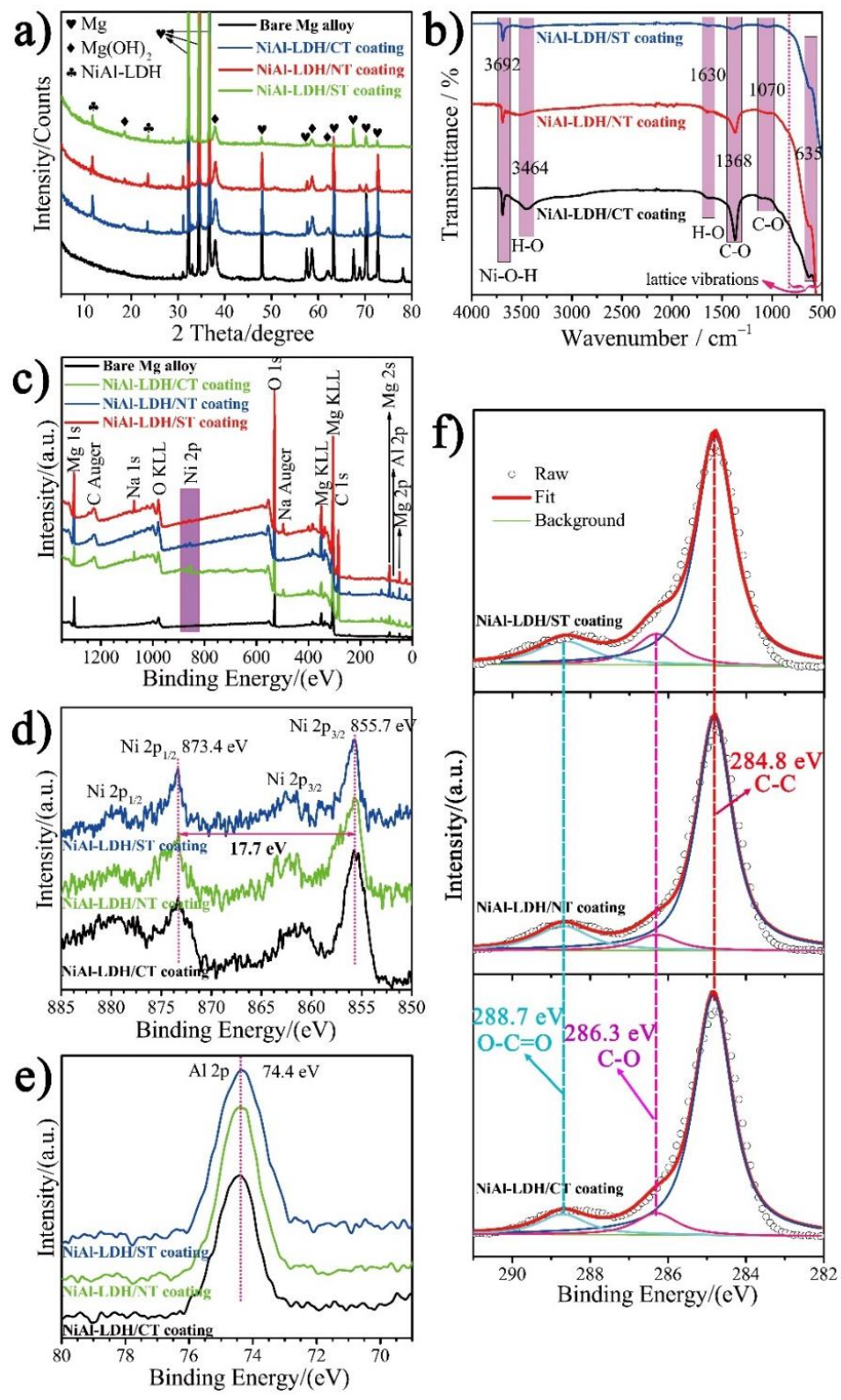

Figure 3. (a) XRD patterns; (b) FT-IR; and (c-f) XPS spectra of different NiAl-LDH coatings. 
Figure 4a-c exhibits the matrix surface fully covered with vertically aligned nanoflake arrays for the NiAl-LDH/CT coating, both vertically and horizontally aligned, and randomly-inclined nanoflakes for the NiAl-LDH/NT coating, and nanonodules for the NiAl-LDH/ST coatings. These coatings are composed of $\mathrm{Ni}, \mathrm{Al}, \mathrm{C}$, and $\mathrm{O}$, and distribute uniformly all over the LDHs coating surfaces (Figure $4 \mathrm{~d}-\mathrm{f}$ ). The thickness and side length of the nanoflakes are 63 and $425 \mathrm{~nm}$, respectively, for NiAl-LDH/CT coating. The thickness of the nanoflakes for NiAl-LDH/NT coating is about $34 \mathrm{~nm}$, and the length cannot be determined due to random orientation and irregular shape which result in a much higher $R_{\mathrm{a}}$, $11.76 \mu \mathrm{m}$, than that of NiAl-LDH/CT coating $(4.24 \mu \mathrm{m})$ (Figure $4 \mathrm{~g}-\mathrm{i})$. The NiAl-LDH/ST coating exhibits a flat surface packed by uniform nanonodules with a size of ca. $17 \mathrm{~nm}$, producing the lowest $R_{\mathrm{a}}, 2.01 \mu \mathrm{m}$, among the three types of NiAl-LDH coatings. The different shapes of the deposits result in different water contact angles (Figure $4 \mathrm{j}-1$ ). The water contact angles of NiAl-LDH/CT and $\mathrm{NiAl-LDH} / \mathrm{NT}$ coatings are $84.8^{\circ}$ and $82.1^{\circ}$, respectively, while the value of NiAl-LDH/ST coating is only $67.9^{\circ}$. The variation in water contact angles led to a slight difference in corrosion inhibition for these coatings.

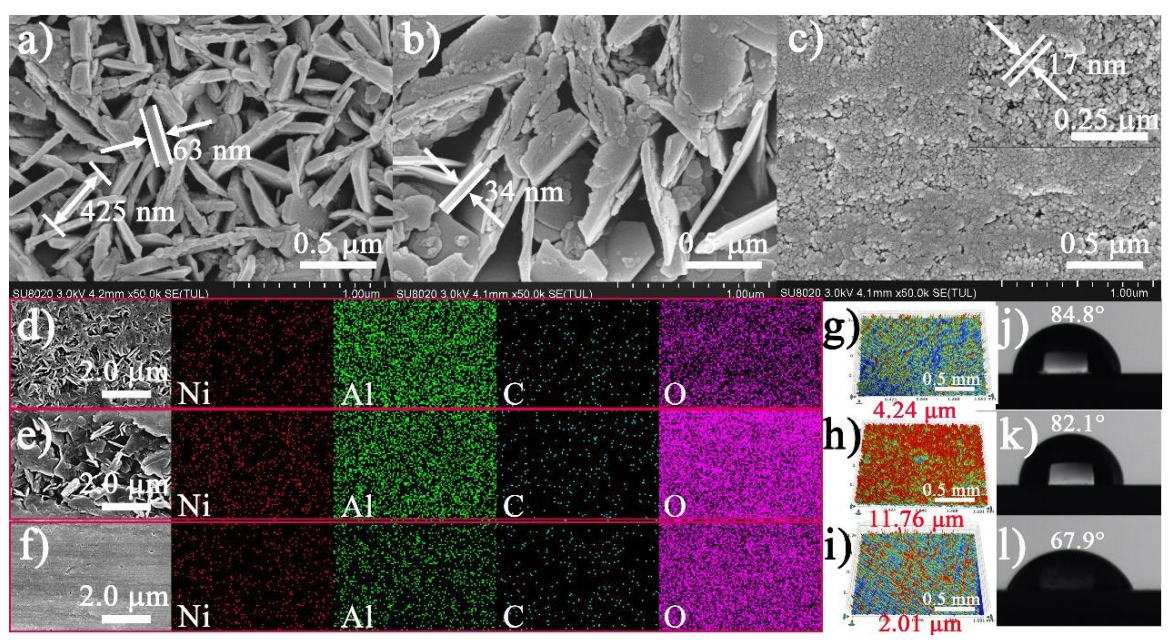

Figure 4. (a-c) SEM; (d-f) SEM-EDS mapping; and (g-i) 3D roughness images of the surface morphologies; and $(\mathbf{j}-\mathbf{l})$ water contact angles for $(\mathbf{a}, \mathbf{d}, \mathbf{g}, \mathbf{j}) \mathrm{NiAl-LDH} / \mathrm{CT},(\mathbf{b}, \mathbf{e}, \mathbf{h}, \mathbf{k}) \mathrm{NiAl-LDH} / \mathrm{NT}$, and $(\mathbf{c}, \mathbf{f}, \mathbf{i}, \mathbf{l}) \mathrm{NiAl}-\mathrm{LDH} / \mathrm{ST}$ coatings.

Electrochemical impedance spectroscopy (EIS) was carried out in $3.5 \mathrm{wt} \% \mathrm{NaCl}$ corrosive electrolyte to evaluate the corrosion resistance of the three NiAl-LDH coatings [22], which is depicted in Figure 5. EIS results show that $\mathrm{Mg}$ alloy has a two-time constant (Figure 5a), i.e., one capacitive loop at high frequency and one inductive loop with ranges from intermediate to low frequency region, which are ascribed to the electric double layer at the electrode/electrolyte interface and relaxation diffusion of corrosion products such as $\mathrm{Mg}(\mathrm{OH})^{+}$ads, respectively [20,23]. According to the fitting results by use of an equivalent circuit (EC) model as given in Figure 6a [20], the charge transfer resistance $\left(R_{\mathrm{ct}}\right)$ of the bare $\mathrm{Mg}$ alloy is only $369.20 \Omega \mathrm{cm}^{2}$. After deposition of NiAl-LDH films, totally different Nyquist plots were observed. The fitting results based on an EC model consisting of $R_{\mathrm{f}}, R_{\mathrm{ct}}$, and $Z_{w}$ (Figure $6 \mathrm{~b}$ ) are listed in Table 2. All the coatings show a very high $R_{\mathrm{f}}$ along with a remarkable increment of $R_{\mathrm{ct}}$, manifesting the significant enhancement of corrosion protection by the coatings. In contrast, NiAl-LDH/CT coating exhibits the highest $R_{\mathrm{f}}\left(6.2 \mathrm{M} \Omega \mathrm{cm}^{2}\right)$ and $R_{\mathrm{ct}}\left(3.5 \mathrm{M} \Omega \mathrm{cm}^{2}\right)$, followed by NiAl-LDH/NT coating with medium $R_{\mathrm{f}}\left(3.7 \mathrm{M} \Omega \mathrm{cm}^{2}\right)$ and $R_{\mathrm{ct}}\left(1.8 \mathrm{M} \Omega \mathrm{cm}^{2}\right)$, and the NiAl-LDH/ST coating with the lowest $R_{\mathrm{f}}\left(1.4 \mathrm{M} \Omega \mathrm{cm}^{2}\right)$ and $R_{\mathrm{ct}}\left(0.72 \mathrm{M} \Omega \mathrm{cm}^{2}\right)$. The impedance modulus at a low frequency, such as $|Z|_{f=0.1 \mathrm{~Hz}}$, which can be obtained directly from the Bode plots without fitting, also represent the corrosion-resistant capability of a coating [20,21]. It can be seen from Table 2 that the NiAl-LDH/CT coating also possesses the highest $|Z|_{f=0.1 \mathrm{~Hz}}, 11.6 \mathrm{M} \Omega \mathrm{cm}^{2}$, 
in comparison with that values of NiAl-LDH/NT $\left(6.7 \mathrm{M} \Omega \mathrm{cm}^{2}\right)$ and NiAl-LDH/ST $\left(3.4 \mathrm{M} \Omega \mathrm{cm}^{2}\right)$ coatings. The biggest radius of curvature in Figure $5 \mathrm{~b}$ also confirms the best corrosion resistance of NiAl-LDH/CT coating.
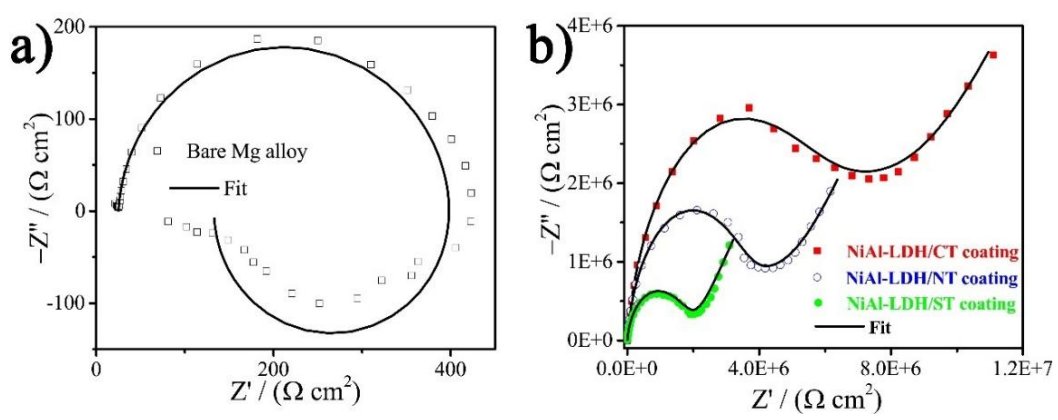

Figure 5. Nyquist plots of (a) bare $\mathrm{Mg}$ alloy and (b) different coatings.
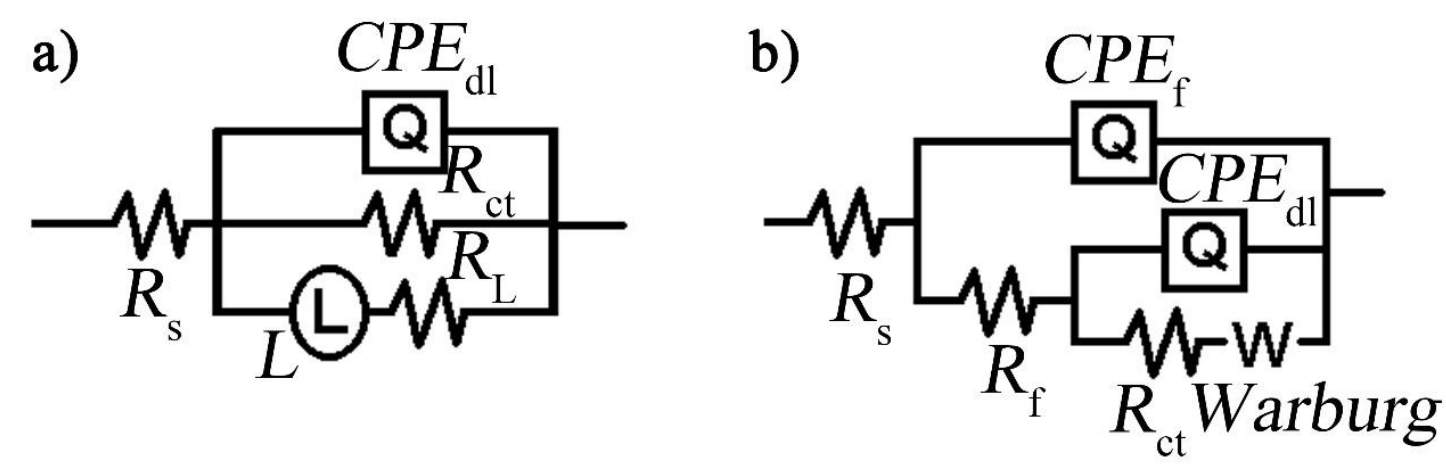

Figure 6. The equivalent circuit models used for fitting the EIS results of the (a) bare Mg alloy and (b) different NiAl-LDH coatings. The equivalent circuit (EC) model of the Mg alloy for fitting is $R_{\mathrm{S}}\left(Q_{\mathrm{dl}} R_{\mathrm{ct}}\left(R_{\mathrm{L}} \mathrm{L}\right)\right)$ where $R_{\mathrm{S}}$ is solution resistance, $Q_{\mathrm{dl}}$ is double layer capacitance, $R_{\mathrm{ct}}$ is charge transfer resistance, $R_{\mathrm{L}}$ is inductance resistance, and $\mathrm{L}$ is inductance. The EC model for coatings is $R_{\mathrm{S}}\left(Q_{\mathrm{f}}\left(R_{\mathrm{f}}\left(Q_{\mathrm{dl}}\left(R_{\mathrm{ct}} Z_{\mathrm{W}}\right)\right)\right)\right)$ where $Q_{\mathrm{f}}$ and $R_{\mathrm{f}}$ are capacitance and resistance of the coatings, respectively. $Z_{\mathrm{W}}$ is Warburg diffusion resistance.

Table 2. Parameters of EIS for three different NiAl-LDH coatings.

\begin{tabular}{|c|c|c|c|c|c|c|c|}
\hline Samples & $\begin{array}{c}Q_{\mathrm{f}} / 10^{-9} \\
\left(\mathrm{~S} \mathrm{~s}^{\mathrm{n}} \mathrm{cm}^{-2}\right)\end{array}$ & $\begin{array}{c}R_{\mathrm{f}} \\
\left(\mathrm{M} \Omega \mathrm{cm}^{2}\right)\end{array}$ & $\begin{array}{c}Q_{\mathrm{dl}} / 10^{-9} \\
\left(\mathrm{~S} \mathrm{~s}^{\mathrm{n}} \mathrm{cm}^{-2}\right)\end{array}$ & $\begin{array}{c}R_{\mathrm{ct}} \\
\left(\mathrm{M} \Omega \mathrm{cm}^{2}\right)\end{array}$ & $\begin{array}{c}W / 10^{-7} \\
\left(\mathrm{~S} \mathrm{~s}^{0.5} \mathrm{~cm}^{-2}\right)\end{array}$ & $\begin{array}{l}|\mathrm{Z}|_{f=0.1 \mathrm{~Hz}} \\
\left(\mathrm{M} \Omega \mathrm{cm}^{2}\right)\end{array}$ & $x^{2} / 10^{-3}$ \\
\hline NiAl-LDH/CT coating & $2.1 \pm 0.029$ & $6.2 \pm 0.17$ & $62.8 \pm 7.6$ & $3.5 \pm 0.45$ & $3.5 \pm 0.17$ & 11.6 & 0.31 \\
\hline NiAl-LDH/NT coating & $1.5 \pm 0.021$ & $3.7 \pm 0.14$ & $113.5 \pm 9.8$ & $1.8 \pm 0.22$ & $3.5 \pm 0.35$ & 6.7 & 0.22 \\
\hline NiAl-LDH/ST coating & $0.84 \pm 0.087$ & $1.4 \pm 0.15$ & $24.5 \pm 2.6$ & $0.72 \pm 0.076$ & $6.9 \pm 0.27$ & 3.4 & 1.5 \\
\hline
\end{tabular}

A further Tafel test was performed to ascertain the corrosion potential, $E_{\text {corr }}$ vs. SCE, and $j_{\text {corr }}$ of the samples [24,25], the results of which are shown in Figure 7 and listed in Table 3 . The $E_{\text {corr }}$ and $j_{\text {corr }}$ of a bare $\mathrm{Mg}$ alloy are $-1450 \mathrm{mV}$ and $3242 \mathrm{nA} \mathrm{cm}^{-2}$, respectively. After deposition of NiAl-LDH/CT film, the $E_{\text {corr }}$ shifts positively by ca. $800 \mathrm{mV}$ to $-674 \mathrm{mV}$, and $j_{\text {corr }}$ is decreased by a factor of 3058 in comparision with that value of the matrix.The $j_{\text {corr }}$ of NiAl-LDH/NT and NiAl-LDH/ST coatings are 3.24 and $5.75 \mathrm{nA} \mathrm{cm}^{-2}$, respectively, which are in positive agreement with the variation of $|Z|_{f=0.1 \mathrm{~Hz}}$ because a coating with higher impedance always has lower $j_{\text {corr }}$ and better corrosion resistance. However, it is worth noting that a material with a lower $j_{\text {corr }}$ does not always possess a higher $E_{\text {corr }}$. For example, the NiAl-LDH/ST coating has the highest $j_{\text {corr }}$ but the lowest $E_{\text {corr }}$ (Table 3 ). That is because $E_{\text {corr }}$ is a thermodynamic parameter, which stands for the corrosion tendency, while corrosion rate is proportional to the $j_{\text {corr }}$, i.e., there is no direct relationship between $E_{\text {corr }}$ and $j_{\text {corr }}$. 

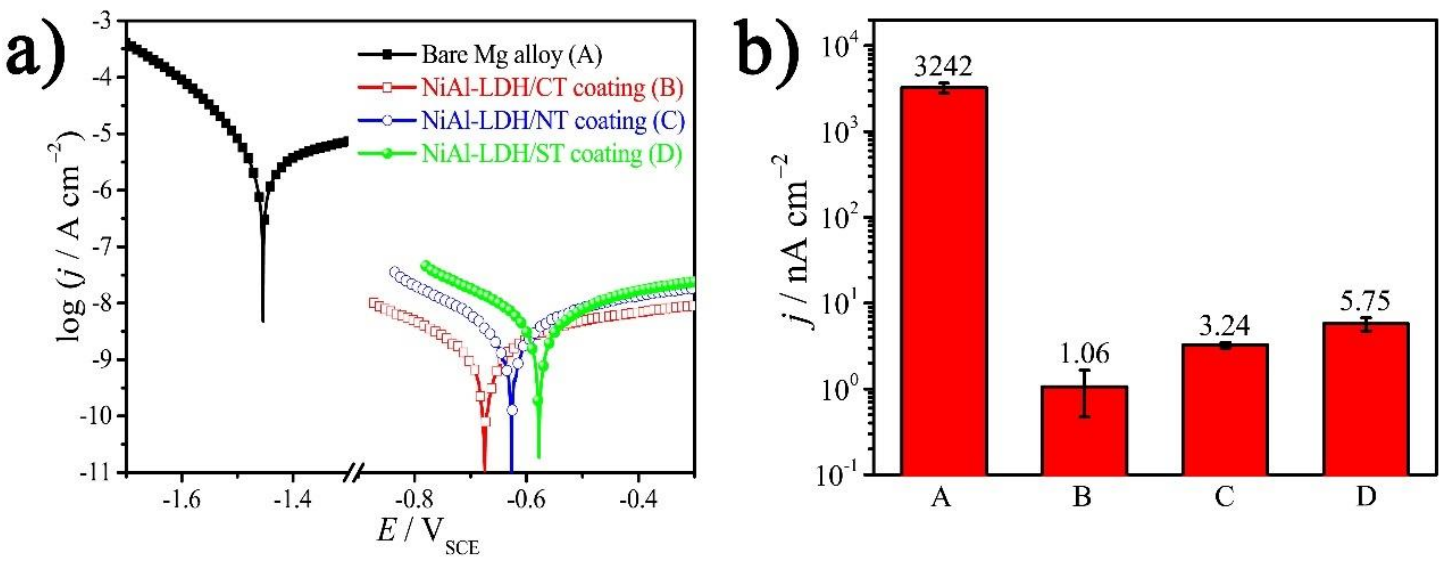

Figure 7. (a) Tafel curves of the bare Mg alloy and different NiAl-LDH coatings in $\mathrm{NaCl}$ corrosive medium. (b) The corresponding $j_{\text {corr }}$ of substrate and coatings extracted from the Tafel curve.

Table 3. Parameters of Tafel curves for bare Mg alloy and different NiAl-LDH coatings.

\begin{tabular}{|c|c|c|c|c|}
\hline Samples & $E_{\text {corr }}(\mathrm{mV})$ & $j_{\text {corr }}\left(\mathrm{nA} \mathrm{cm}^{-2}\right)$ & $\beta_{\mathrm{a}}\left(\mathrm{mV} \mathrm{\operatorname {dec } ^ { - 1 }}\right)$ & $-\beta_{\mathrm{c}}\left(\mathrm{mV} \mathrm{dec}^{-1}\right)$ \\
\hline Bare Mg alloy & $-1450 \pm 52$ & $3242 \pm 425$ & 331 & 95 \\
\hline NiAl-LDH/CT coating & $-674 \pm 42$ & $1.06 \pm 0.59$ & 190 & 171 \\
\hline NiAl-LDH/NT coating & $-625 \pm 96$ & $3.24 \pm 0.25$ & 244 & 184 \\
\hline NiAl-LDH/ST coating & $-577 \pm 51$ & $5.75 \pm 1.03$ & 270 & 188 \\
\hline
\end{tabular}

The high capacity and slight difference in corrosion resistance of the three different NiAl-LDH coatings are ascribed to the high affinity of $\mathrm{LDHs}$ towards $\mathrm{CO}_{3}{ }^{2-}$ in comparison with the corrosive $\mathrm{Cl}^{-}$, the different orientations of the nanosheets, and the different shapes of the deposition, which is illustrated in Figure 1. The corrosive species cannot be exchanged with the brucite-like layer and have to exchange with the $\mathrm{CO}_{3}{ }^{2-}$ anions to arrive at the substrate surface, but the ion-exchange is not easy due to the high affinity of $\mathrm{LDHs}$ to $\mathrm{CO}_{3}{ }^{2-}$ anions, enabling high enhancement in corrosion inhibition in all the as-prepared NiAl-LDH coatings. Due to the vertically-aligned nanosheets in the $\mathrm{NiAl-LDH} / \mathrm{CT}$ coating, the carbonate anions distribute evenly in the interlayer spaces, which further increase the difficulty of the ion-exchange between $\mathrm{CO}_{3}{ }^{2-}$ anions and corrosive species (Case I in Figure 1). For the NiAl-LDH/NT coating, the basal spacing becomes larger at some locations and $\mathrm{CO}_{3}{ }^{2-}$ anions distribute unevenly in the interlayer spaces owing to irregular orientation of the nanosheets, which increases the probability for corrosive species to arrive at the substrate surface by going through fewer $\mathrm{CO}_{3}{ }^{2-}$ anions, resulting in reduction of corrosion inhibition (Case II in Figure 1). In general, the dense plate-like arrangement of LDHs is favorable for increasing corrosion resistance of the film due to lower exposure of $\mathrm{CO}_{3}{ }^{2-}$ anions for ion-exchange. However, for the NiAl-LDH/ST coating in this work, nanomodules with many obvious voids rather than nanoflakes were formed, as demonstrated by the SEM image in Figure 4c, which decreases the corrosion-resistant capability of the LDHs film. In addition, the smaller water contact angle of NiAl-LDH/ST coating in comparison with that of NiAl-LDH/CT and NiAl-LDH/NT coatings should also be responsible for the decreasing corrosion inhibition of NiAl-LDH/ST coating. It is worth noting that although these explanations above account for the difference in corrosion resistance of the three different coatings, the influences of the different orientation and shapes of the deposition on the corrosion inhibition are not significant because all the $j_{\text {corr }}$ of the coatings remain in the level of $\mathrm{nA} \mathrm{cm}^{-2}$.

\section{Conclusions}

A facile hydrothermal strategy was progressed to achieve in-situ NiAl-LDH coatings on Mg alloy to improve the corrosion protection. All the NiAl-LDH coatings obtained by different nickel salts show 
remarkable enhancement in corrosion inhibition in $\mathrm{NaCl}$ solution compared with $\mathrm{Mg}$ alloy substrate, which is attributed to the strongly affinity between charge-compensating $\mathrm{CO}_{3}{ }^{2-}$ and brucite-like layers. The different orientation of the nanosheets and the different shapes of the deposition are mainly responsible for the slight difference in corrosion inhibition performance among the three different coatings. The NiAl-LDH/CT coating deposited by carbonate shows relatively the highest $|Z|_{f=0.1 \mathrm{~Hz}}$ and lowest $j_{\text {corr }}$, suggesting its best corrosion inhibition. It is believed that these findings may inspire the design and development of other LDH nanosheet arrays, such as NiCr-LDH arrays, as highly enhanced corrosion protection film for a susceptible lightweight metal matrix.

Author Contributions: The conceptualization of the work was conceived by Z.-H.X. The experiments were mainly carried out by X.Y. Z.J. revised and edited the article. Some electrochemical tests were carried out by L.L. Z.-H.X. supervised all the experiments, discussed the results with all the authors, and reviewed and revised the manuscript.

Funding: This research was funded by the National Natural Science Foundation of China $(51501157,21571148)$; the Fundamental Research Funds of China West Normal University (17B005); and the Chemical Synthesis and Pollution Control Key Laboratory of Sichuan Province (CSPC2014-4-2).

Conflicts of Interest: The authors declare no conflict of interest.

\section{References}

1. Xie, Z.-H.; Li, D.; Skeete, Z.; Sharma, A.; Zhong, C.-J. Nanocontainer-Enhanced Self-Healing for Corrosion-Resistant Ni Coating on Mg Alloy. ACS Appl. Mater. Interfaces 2017, 9, 36247-36260. [CrossRef] [PubMed]

2. Zhang, J.; Xie, Z.-H.; Chen, H.; Hu, C.; Li, L.; Hu, B.; Song, Z.; Yan, D.; Yu, G. Electroless Deposition and Characterization of a Double-Layered Ni-B/Ni-P Coating on AZ91D Mg Alloy from Eco-Friendly Fluoride-Free Baths. Surf. Coat. Technol. 2018, 342, 178-189. [CrossRef]

3. Xie, Z.H.; Chen, F.; Xiang, S.; Zhou, J.; Song, Z.; Yu, G. Studies of Several Pickling and Activation Processes for Electroless Ni-P Plating on AZ31 Magnesium Alloy. J. Electrochem. Soc. 2015, 162, D115-D123. [CrossRef]

4. Rajabalizadeh, Z.; Seifzadeh, D. Application of Electroless Ni-P Coating on Magnesium Alloy via $\mathrm{CrO}_{3} / \mathrm{HF}$ Free Titanate Pretreatment. Appl. Surf. Sci. 2017, 422, 696-709. [CrossRef]

5. Duan, C.; Zhao, J.; Qin, L.; Yang, L.; Zhou, Y. Ternary Ni-Co-Mo Oxy-Hydroxide Nanoflakes Grown on Carbon Cloth for Excellent Supercapacitor Electrodes. Mater. Lett. 2017, 208, 65-68. [CrossRef]

6. Wang, L.; Wang, Y.; Feng, X.; Ye, X.; Fu, J. Small-Sized Mg-Al LDH Nanosheets Supported on Silica Aerogel with Large Pore Channels: Textural Properties and Basic Catalytic Performance after Activation. Nanomaterials 2018, 8, 113. [CrossRef] [PubMed]

7. Ding, Y.; Liu, L.; Fang, Y.; Zhang, X.; Lyu, M.; Wang, S. The Adsorption of Dextranase onto Mg/Fe-Layered Double Hydroxide: Insight into the Immobilization. Nanomaterials 2018, 8, 173. [CrossRef] [PubMed]

8. Zhang, G.; Wu, L.; Tang, A.; Zhang, S.; Yuan, B.; Zheng, Z.; Pan, F. A Novel Approach to Fabricate Protective Layered Double Hydroxide Films on the Surface of Anodized Mg-Al alloy. Adv. Mater. Interfaces 2017, 4, 1700163. [CrossRef]

9. Guo, L.; Wu, W.; Zhou, Y.; Zhang, F.; Zeng, R.; Zeng, J. Layered Double Hydroxide Coatings on Magnesium Alloys: A Review. J. Mater. Sci. Technol. 2018. [CrossRef]

10. Wu, L.; Yang, D.; Zhang, G.; Zhang, Z.; Zhang, S.; Tang, A.; Pan, F. Fabrication and Characterization of Mg-M Layered Double Hydroxide Films on Anodized Magnesium Alloy AZ31. Appl. Surf. Sci. 2018, 431, 177-186. [CrossRef]

11. Zhang, F.; Liu, Z.-G.; Zeng, R.-C.; Li, S.-Q.; Cui, H.-Z.; Song, L.; Han, E.-H. Corrosion Resistance of Mg-Al-LDH Coating on Magnesium Alloy AZ31. Surf. Coat. Technol. 2014, 258, 1152-1158. [CrossRef]

12. Yan, L.; Zhou, M.; Zhang, X.; Huang, L.; Chen, W.; Roy, V.A.L.; Zhang, W.; Chen, X. A Novel Type of Aqueous Dispersible Ultrathin-Layered Double Hydroxide Nanosheets for in Vivo Bioimaging and Drug Delivery. ACS Appl. Mater. Interfaces 2017, 9, 34185-34193. [CrossRef] [PubMed]

13. Peng, F.; Wang, D.; Tian, Y.; Cao, H.; Qiao, Y.; Liu, X. Sealing the Pores of PEO Coating with Mg-Al Layered Double Hydroxide: Enhanced Corrosion Resistance, Cytocompatibility and Drug Delivery Ability. Sci. Rep. 2017, 7, 8167. [CrossRef] [PubMed] 
14. Peng, F.; Li, H.; Wang, D.; Tian, P.; Tian, Y.; Yuan, G.; Xu, D.; Liu, X. Enhanced Corrosion Resistance and Biocompatibility of Magnesium Alloy by Mg-Al-Layered Double Hydroxide. ACS Appl. Mater. Interfaces 2016, 8, 35033-35044. [CrossRef] [PubMed]

15. Ni, J.; Xue, J.; Xie, L.; Shen, J.; He, G.; Chen, H. Construction of Magnetically Separable NiAl $\mathrm{LDH} / \mathrm{Fe}_{3} \mathrm{O}_{4}$-RGO Nanocomposites with Enhanced Photocatalytic Performance under Visible Light. Phys. Chem. Chem. Phys. 2018, 20, 414-421. [CrossRef] [PubMed]

16. Peng, F.; Wang, D.; Cao, H.; Liu, X. Loading 5-Fluorouracil into Calcined Mg/Al Layered Double Hydroxide on AZ31 Via Memory Effect. Mater. Lett. 2018, 213, 383-386. [CrossRef]

17. Zhou, M.; Yan, L.; Ling, H.; Diao, Y.; Pang, X.; Wang, Y.; Gao, K. Design and Fabrication of Enhanced Corrosion Resistance Zn-Al Layered Double Hydroxides Films Based Anion-Exchange Mechanism on Magnesium Alloys. Appl. Surf. Sci. 2017, 404, 246-253. [CrossRef]

18. Zhang, G.; Wu, L.; Tang, A.; Weng, B.; Atrens, A.; Ma, S.; Liu, L.; Pan, F. Sealing of Anodized Magnesium Alloy AZ31 with MgAl Layered Double Hydroxides Layers. RSC Adv. 2018, 8, 2248-2259. [CrossRef]

19. Li, D.; Chen, F.; Xie, Z.-H.; Shan, S.; Zhong, C.-J. Enhancing Structure Integrity and Corrosion Resistance of $\mathrm{Mg}$ Alloy by a Two-Step Deposition to Avoid F Ions Etching to Nano-SiO 2 Reinforcement. J. Alloy. Compd. 2017, 705, 70-78. [CrossRef]

20. Xie, Z.-H.; Shan, S. Nanocontainers-Enhanced Self-Healing Ni Coating for Corrosion Protection of Mg Alloy. J. Mater. Sci. 2018, 53, 3744-3755. [CrossRef]

21. Zeng, R.-C.; Liu, Z.-G.; Zhang, F.; Li, S.-Q.; Cui, H.-Z.; Han, E.-H. Corrosion of Molybdate Intercalated Hydrotalcite Coating on AZ31 Mg Alloy. J. Mater. Chem. A 2014, 2, 13049-13057. [CrossRef]

22. Chen, Y.; Zhang, J.; Dai, N.; Qin, P.; Attar, H.; Zhang, L.-C. Corrosion Behaviour of Selective Laser Melted Ti-TiB Biocomposite in Simulated Body Fluid. Electrochim. Acta 2017, 232, 89-97. [CrossRef]

23. Gan, R.; Wang, D.; Xie, Z.-H.; He, L. Improving Surface Characteristic and Corrosion Inhibition of Coating on Mg Alloy by Trace Stannous (II) Chloride. Corros. Sci. 2017, 123, 147-157. [CrossRef]

24. Dai, N.; Zhang, J.; Chen, Y.; Zhang, L.-C. Heat Treatment Degrading the Corrosion Resistance of Selective Laser Melted Ti-6Al-4V Alloy. J. Electrochem. Soc. 2017, 164, C428-C434. [CrossRef]

25. Chen, Y.; Zhang, J.; Gu, X.; Dai, N.; Qin, P.; Zhang, L.-C. Distinction of Corrosion Resistance of Selective Laser Melted Al-12Si Alloy on Different Planes. J. Alloy. Compd. 2018, 747, 648-658. [CrossRef]

(C) 2018 by the authors. Licensee MDPI, Basel, Switzerland. This article is an open access article distributed under the terms and conditions of the Creative Commons Attribution (CC BY) license (http:/ / creativecommons.org/licenses/by/4.0/). 